\title{
Interactive comment on "Identification of Hotspots of Rainfall Variation Sensitive to Indian Ocean Dipole Mode through Intentional Statistical Simulations” by Jong-Suk Kim et al.
}

Louise Slater (Editor)

louise.slater@ouce.ox.ac.uk

Received and published: 19 August 2019

Dear Authors,

We have received two reviews of your manuscript, "Identification of Hotspots of Rainfall Variation Sensitive to Indian Ocean Dipole Mode through Intentional Statistical Simulations". After a careful re-reading of the manuscript as well as the two reviews, I am sorry to say that I cannot recommend publication of your work in HESS, and therefore I recommend withdrawal of the manuscript (in this case, the response to reviewers is not required).

Printer-friendly version

Discussion paper 
The reviewers both raise some valid concerns regarding the work, namely regarding: the clarity of the methods (description of the indices, their construction, and the discussion of the physical mechanisms involved); the novelty of the study (including how it is framed in light of earlier research); the attention to detail (including the design of the figures, and utility of the dry season analysis).

I hope these suggestions may be helpful in revising the manuscript and resubmitting it elsewhere.

\section{Sincerely, Louise Slater}

Interactive comment on Hydrol. Earth Syst. Sci. Discuss., https://doi.org/10.5194/hess-2019217, 2019. 